\title{
Attitudes towards Young People in Bulgaria
}

\author{
Stanislava Stoyanova \\ Department of Psychology, South-West University "Neofit Rilski”, Blagoevgrad, Bulgaria. \\ Email: avka@swu.bg \\ Received August 22 $2^{\text {nd }}, 2011$; revised September 23 ${ }^{\text {rd }}, 2011$; accepted October $11^{\text {th }}, 2011$.
}

\begin{abstract}
This paper presents a study of the stereotypes of and attitudes towards young people in Bulgaria. The method was developed on the basis of Fishbein's and Ajzen theory and using several coding matrices for content analysis by a group of psychologists during the summer school "Social cognition" held in Blagoevgrad, Bulgaria in July 2010. The social involvement of young people, life satisfaction and family issues were studied.
\end{abstract}

Keywords: Attitudes, Youth, Life Satisfaction, Social Involvement

\section{Introduction}

Attitudes are usually conceived as evaluative appraisals (Leone, Perugini, \& Ercolani, 1999), a person's favourable or unfavourable evaluation of a social object (Fishbein \& Ajzen, 1975; Meshel \& McGlynn, 2004). The attitudes toward youth include the image of a young person-student, the intentions to interact with a young person-student, the beliefs that young people - students can take part in academic and non-academic classes (Siperstein et al., 2007).

According to the tripartite or hierarchical model of attitudes described by McGuire (1986), attitudes have cognitive, affecttive, and behavioural response tendencies. Cognitive components of the attitudes are beliefs that can be defined as a person's knowledge or information about an attitude object (Fishbein \& Ajzen, 1975). A person's attitude is related to a set of intentions to behave certain ways toward an attitude object (Meshel \& McGlynn, 2004).

The Fishbein-Ajzen model contains two composite variables which determine how an individual intends to behave. One variable, the attitude, consists of the beliefs about and evaluations of the consequences of a specific form of behaviour. The other variable is a summary measure of the norms attributed to relevant others (e.g. parents, friends) and the extent to which someone tends to conform to these expectations (Knibbe, Oostveen, \& Van De Goor, 1991).

As a part of the expectancy-value approach, the direct predictor of behaviour is intention that is function of attitude toward the act (a personal evaluative response), and subjective norms (the social information available and the perceived social pressure to behave). The Ajzen's Theory of Planned Behaviour (TPB) claims that perceived behavioural control (defined as the perception of how difficult or easy an action is to perform for a given subject) interacts with attitudes and subjective norms in order to create intention to behave. The greater is the perceived behavioural control, the more positive is the behavioural intention and the more likely is the performance of behaviour. The Bagozzi's (1992) Theory of Self-regulation (TSR) claims that desire interacts with attitudes and subjective norms and leads to intention (in Leone, Perugini, \& Ercolani, 1999).

Among young men in The Netherlands frequency of past behaviour contributed more to the present habits and behaviour than the beliefs, norms and perceived skills that the FishbeinAjzen model assumed (Knibbe, Oostveen, \& Van De Goor, 1991).

\section{Findings about Attitudes towards Young People}

The eight years old children in USA held primarily negative attitudes toward older persons. Three quarters of the younger sample preferred to be with younger people. Older persons had positive attitudes toward younger persons. Older persons' attitudes toward young people (age 11 - 13) became significantly more positive after a long contact with them (for several weeks in the process of cross-age education) (Meshel \& McGlynn, 2004).

Normative youth's attitudes toward integrating detached youth within normative youth settings in USA were positive (Romi, 1999). Children and youth in USA hold negative attitudes toward their peers with intellectual disabilities (Siperstein et al., 2007).

Those who know most of the young people in their area in Scotland were much more likely than those who know none to have positive attitudes towards young people. Those adults who have least contact with young people were more likely to have negative views of the young person (Anderson, Bromley, \& Given, 2005).

Discussion with peers, direct contact with a non-stereotypic target, and increasing knowledge of target group persons were effective in producing positive attitude change toward target group with the direct contact approach proving to be the most effective (Meshel \& McGlynn, 2004).

\section{Measuring Attitudes}

The attitudes could be measured by means of questionnaires, group interviews (Knibbe, Oostveen, \& Van De Goor, 1991), semantic-differential 7-point scales defined as positive/negative (Leone, Perugini, \& Ercolani, 1999; Meshel \& McGlynn, 2004), list of the most important persons for the subject and indicating how much each of them would approve or disapprove some kind of behaviour, indicating on a 7-point scale how easy or difficult it is for the subject to behave in a defined way, indicating on a 7-point scale own desire to behave in a defined way, indicating on a 7-point scale the likelihood to behave in a defined way, indicating on a 7-point scale the frequency of past behaviour (Leone, Perugini, \& Ercolani, 1999), a short paper describing the target group, interviews, photographs of unfamiliar members of the target group (Meshel \& McGlynn, 2004), a participant information sheet, a written vignette describing the target group, an attitude and beliefs rating scale containing 
about 40 statements presented as 4-point Likert-scale items from 1 strongly agree to 4 strongly disagree (Stinnett, Cruce, \& Choate, 2004).

An attitude toward a person or object is appropriately measured by having an individual place an object on a bipolar affecttive or evaluative dimension (Fishbein \& Ajzen, 1975; Meshel \& McGlynn, 2004).

\section{Method}

An attitude scale based on Fishbein and Ajzen model was developed (Stoyanova et al., 2010) using stereotypes to define young people across cultures mainly based on Bolzan and colleagues' research findings (Bolzan, 2003). The attitude scale was designed to assess both young and elderly people's attitudes toward young people (13 - 25 years old). It consists of 18 stereotypes about young people which are common in the present literature. The sample item for a positive stereotype is "hard-working" and the sample item for a negative stereotype is "selfish". Respondents are required to indicate how positive or negative is each item to them on a 7 point scale $(-3=$ extremely negative; $+3=$ extremely positive). Scoring of the scale is based on the formula developed by Fishbein and Ajzen (1975) which is $A=\sum\left(b^{*} e\right)$. In this formula, A stands for the attitude, $\sum$ is sum, b is how typical is the belief, * is multiply and e stands for how positive or negative is the quality (Fishbein, 1967: p. 394).

Two questions about life satisfaction were included on the basis of the suggestive research evidence (Meshel \& McGlynn, 2004) and expert agreement (Stoyanova et al., 2010) about the link between life satisfaction and attitudes toward young people. Those questions are rated on a seven point semantic differential scale where 1 means unsatisfied and 7 means satisfied with the life. Furthermore questions about demographic information were included in the end of the questionnaire (Stoyanova et al., 2010).

A content analysis matrix was prepared on the basis of the content analysis matrices and results from previous studies (Anglin et al., 2000; Lampman et al., 2002; Ward, 2005; Bolzan, 2003) by a group of 7 psychologists during the European Summer School "Social Cognition" held in Blagoevgrad, Bulgaria in July 2010, organized by the European Federation of Psychology Students' Associations, and the Association of Young Psychologists In Bulgaria "4th April" in the campus of South-West University "Neofit Rilski” (Stoyanova et al., 2010). This content analysis matrix was created to study media representations of the age group from 13 to 25 years old. A content analysis of September 2010 issues of two print Bulgarian daily newspapers ("Sega" and "Telegraph") was carried out. A total of 159 articles dedicated to young people (36 in "Sega" and 123 in "Telegraph") were coded according to key topics like the focus of the article (22 foci were enumerated and among them were family issues), and the attitude towards young people expressed by the source of the material cited and the news item.

\section{Hypotheses}

1) Young people will have more positive attitudes towards young people; teenagers will have a more positive attitude towards young people than people older than 20; elderly people will have negative attitudes about young people (because of the in-group favouritism-Turner, 1990; and because the advance in age is related to increase in prejudices-Wagner \& Zick, 1995).
2) Other socio-demographic groups (educational, gender, with different family and social status) will differ in their attitudes towards young people.

3) People who feel satisfied from their life are more likely to have positive attitude towards young people (because they do not consider the attitude of their environment as hostile, and they feel community with other people-Adler, 1920: p. 103).

4) The image of young people reflected by the media is predominantly a positive one.

\section{Participants}

This research was designed as a cross-sectional survey. The ideal sample size for the preliminary studies is recommended as 100 (Prince, Stewart, Ford, \& Hotopf, 2003).

The research was carried out from 1 September 2010 to 23 November 2010. The participants were approached personally. They were given information sheets and consent forms to help them with making informed decisions about their participation in the study. Then the consenting participants were administered the attitude scale.

114 subjects in Bulgaria from 18 to 62 years old were studied. Their mean age was 22 years old ( $\mathrm{SD}=9$ years). 88 respondents $(80.7 \%)$ were from 18 to 20 years old. 8 respondents were from 21 to 30 years old. 6 respondents were from 31 to 40 years old. 5 respondents were from 41 to 50 years old. 5 respondents were from 51 to 60 years old. 2 respondents were from 61 to 65 years old.

88 were women $(78 \%)$ and 26 were men $(22 \%) .17$ were married (14.9\%). 97 were single (85.1\%). 98 did not have any children (86\%). 8 had 1 child $(7 \%)$ and 8 had 2 children (7\%).

86 graduated from high school $(75.4 \%) .13$ graduated from lyceum (11.4\%). 2 graduated from technical school (1.8\%). 11 graduated from university (9.6\%). 2 hold a PhD degree (1.8\%).

91 were students $(79.8 \%)$ in speech pathology 2 nd year, psychology 1st year, public administration 1st year. 20 were workers (17.5\%) - psychologists, accountants, administrators, barwomen, dispatchers, electricians, managers, social workers, teachers, and waitresses. 2 were pensioners $(1.8 \%)$. 1 was unemployed $(.9 \%)$.

\section{Results}

The participants in Bulgaria estimated as positive the quailties like capable (by $96.6 \%^{1}$; mean $=2.6 ; \mathrm{SD}=.773$ ); intelligent (by $93.9 \%$; mean $=2.48 ; \mathrm{SD}=.885$ ); hard-working (by $96.5 \%$; mean $=2.45 ; \mathrm{SD}=.883$ ); self-assured (by $97.4 \%$; mean $=2.39 ; \mathrm{SD}=.805)$; fun loving (by $97.3 \%$; mean $=2.21 ; \mathrm{SD}$ $=.749$ ); optimistic (by 93.9\%; mean $=2.11$; SD = 1.067); enthusiastic (by $93.7 \%$; mean $=1.85 ; \mathrm{SD}=1.076$ ); easygoing (by $86.7 \%$; mean $=1.83 ; \mathrm{SD}=1.195)$; involved in social issues (by $85.9 \%$; mean $=1.7 ; \mathrm{SD}=1.197)$; risk-taking $($ by $81.5 \%$; mean $=1.28 ; \mathrm{SD}=.982)$. The most positively estimated qualities were inherent. Less positively estimated qualities were these ones that a person should put some efforts to achieve them.

The participants in Bulgaria estimated as negative the quailties and the behaviours such as taking drugs (by $97.4 \%{ }^{2}$; mean $=-2.84 ; \mathrm{SD}=.759$ ); excessive drinking (by 92.9\%; mean $=$ $-2.5 ; \mathrm{SD}=1.135$ ); smoking (by $87.7 \%$; mean $=-2.1$; $\mathrm{SD}=$

${ }^{1}$ This percentage is the sum of the percentages of all positive categories of the scale.

${ }^{2}$ This percentage is the sum of the percentages of all negative categories of the scale. 
1.324); lonely (by $83.3 \%$; mean $=-1.9$; $\mathrm{SD}=1.296$ ); selfish (by $62.8 \%$; mean $=-1.08 ; \mathrm{SD}=1.648$ ); misunderstood (by $45.1 \%$; mean $=-.88 ; \mathrm{SD}=1.174)$; frightened (by $68.5 \%$; mean $=-.86 ; \mathrm{SD}=1.6$ ); carefree (by $55.3 \%$; mean $=-.57 ; \mathrm{SD}=$ 1.574). Lonely, selfish and frightened are some negative traits that are parts of the anti-social attitude and feeling of inferiority (Adler, 1920: pp. 75-76).

Surprisingly, risk - taking was evaluated as a positive quality, and carefree-as a negative one.

There were no significant differences in respondents' opinions $(p>.05)$ how typical were for young people from 13 to 19 and from 20 to 25 the qualities and behaviours such as excessive drinking, frightened, optimistic, risk-taking and lonely. For all other characteristics, the respondents differed significantly in their attribution to young people from 13 to 19 and from 20 to $25(\mathrm{p}<.05)$.

The respondents in Bulgaria estimated as typical for 13 to 19 year-old the qualities and the behaviours like fun loving (by $95.5 \%$; mean $=2.6 ; \mathrm{SD}=.776$ ); smoking (by $87.2 \%$; mean $=$ $1.88 ; \mathrm{SD}=1.601$ ); carefree (by $86.8 \%$; mean $=1.88 ; \mathrm{SD}=$ 1.351 ); excessive drinking (by $84 \%$; mean $=1.42$; $\mathrm{SD}=1.552$ ); optimistic (by $81.2 \%$; mean $=1.42 ; \mathrm{SD}=1.522$ ); risk-taking (by $77.3 \%$; mean $=1.33$; $\mathrm{SD}=1.472$ ); selfish (by $73.2 \%$; mean $=1.23 ; \mathrm{SD}=1.464)$; self-assured (by $72.1 \%$; mean $=1.08 ; \mathrm{SD}$ $=1.496$ ); misunderstood (by $61.6 \%$; mean $=1.06 ; \mathrm{SD}=1.384$ ); taking drugs (by $68.7 \%$; mean $=.83$; $\mathrm{SD}=1.482$ ); easygoing (by $67.3 \%$; mean $=.83 ; \mathrm{SD}=1.477$ ); intelligent (by $67 \%$; mean $=.75 ; \mathrm{SD}=1.424)$; capable $($ by $64.9 \% ;$ mean $=.72 ; \mathrm{SD}=$ 1.329 ); enthusiastic (by $65.7 \%$; mean $=.7 ; \mathrm{SD}=1.61$ ); frightened (by $47.3 \%$; mean $=.23$; $\mathrm{SD}=1.512$ ).

The participants in Bulgaria estimated as non-typical for 13 to 19 year-old the qualities and the behaviours such as involved in social issues (by $51.8 \%$; mean $=-.53$; $\mathrm{SD}=1.734$ ); hardworking (by $53.2 \%$; mean $=-.52$; $\mathrm{SD}=1.67$ ); lonely (by $39.3 \%$; mean $=-.25 ; \mathrm{SD}=1.647$ ).

The respondents in Bulgaria estimated as typical for 20 to 25 year-old the qualities and the behaviours like fun loving (by $93.8 \%$; mean $=2.39 ; \mathrm{SD}=.953$ ); capable (by $87.4 \%$; mean $=$ $1.7 ; \mathrm{SD}=1.023$ ); smoking (by $83.6 \%$; mean $=1.66 ; \mathrm{SD}=$ 1.593 ); self-assured (by 64.5\%; mean $=1.66$; $\mathrm{SD}=1.136$ ); risk-taking (by $87.5 \%$; mean $=1.45 ; \mathrm{SD}=1.038$ ); intelligent (by $82 \%$; mean $=1.42 ; \mathrm{SD}=1.014$ ); easygoing (by $78.9 \%$; mean $=1.3 ; \mathrm{SD}=1.159$ ); enthusiastic (by $83.2 \%$; mean $=1.21$; $\mathrm{SD}=1.235$ ); excessive drinking (by $80.3 \%$; mean $=1.16$; $\mathrm{SD}=$ 1.529 ); hard-working (by 78.3\%; mean $=1.15$; $\mathrm{SD}=1.447$ ); optimistic (by 78.4\%; mean $=1.13$; $\mathrm{SD}=1.415$ ); involved in social issues (by $67.9 \%$; mean $=.8 ; \mathrm{SD}=1.576$ ); selfish (by $63.4 \%$; mean $=.72 ; \mathrm{SD}=1.466$ ); taking drugs (by $50 \%$; mean $=.33 ; \mathrm{SD}=1.521$ ); carefree (by $53.2 \%$; mean = .2; $\mathrm{SD}=1.654$ ); misunderstood (by $36 \%$; mean $=.15 ; \mathrm{SD}=1.185$ ); frightened (by $46.4 \%$; mean $=.13 ; \mathrm{SD}=1.271$ ).

The participants in Bulgaria estimated as non-typical for 20 to 25 year-old the qualities such as lonely (by $38.7 \%$; mean = $-.32 ; \mathrm{SD}=1.596)$.

The participants had positive attitudes towards young people from 13 to 19 years old (by $59.6 \%$; mean $=5.59$; $\mathrm{SD}=22.297$ ) and towards young people from 20 to 25 years old (by $88.6 \%$; mean $=24.89 ; \mathrm{SD}=21.897)$. Their attitude towards young people from 13 to 19 years old was significantly more positive than their attitude towards young people from 20 to 25 years old $(\mathrm{t}|113|=8.847 ; \mathrm{p}=.0001)$. The positive attitude towards 13-19 year-old was related to a positive attitude towards $20-25$ year-old $(\mathrm{r}=.445 ; \mathrm{p}=.0001)$.

The older respondents (more than 20 years old; mean $=16.48$;
$\mathrm{SD}=25.085)$ had a more positive attitude towards young people from 13 to 19 years old than the younger respondents (up to 20 years old; mean $=3.09 ; \mathrm{SD}=21.241)$ did $(\mathrm{t}|107|=2.504 ; \mathrm{p}$ $=.014$ ). The older respondents (more than 20 years old; mean = $24 ; \mathrm{SD}=26.06$ ) and the younger respondents (up to 20 years old; mean $=25.86$; $\mathrm{SD}=21.174$ ) did not differ significantly in their attitudes towards young people from 20 to $25(\mathrm{t}|107|$ $=.346 ; \mathrm{p}=.73$ ).

The increase of the participants' age was related to a more positive attitude towards 13 - 19 year-old (stepwise regression; $\mathrm{F}=8.361 ; \mathrm{p}=.005 ; \mathrm{R}=.268 ; \mathrm{R} 2=.072 ; \mathrm{t}=2.892 ; \mathrm{p}=.005 ; \mathrm{b}$ $=.697)$, but life satisfaction now $(\mathrm{t}=.899 ; \mathrm{p}=.37)$ and expected life satisfaction in the future $(\mathrm{t}=1.379 ; \mathrm{p}=.171)$ were not.

The most part of the respondents were satisfied with life (by $61.8 \%$; mean $=4.89 ; \mathrm{SD}=1.39)$ and they expected to be significantly more satisfied with life in the future (by $91.8 \%$; mean $=6.02 ; \mathrm{SD}=1.133 ; \mathrm{t}|109|=9.691 ; \mathrm{p}=.0001)$. Their attitude towards life was mainly optimistic. Life satisfaction now was related to life satisfaction in the future $(\mathrm{r}=.549 ; \mathrm{p}=.0001)$ and to a positive attitude toward $20-25$ year-old $(\mathrm{r}=.222 ; \mathrm{p}=.02)$.

The increase of the participants' life satisfaction in the present time was related to a more positive attitude towards $20-25$ year-old (stepwise regression; $\mathrm{F}=5.446 ; \mathrm{p}=.021 ; \mathrm{R}=.219$; $\mathrm{R} 2=.048 ; \mathrm{t}=2.334 ; \mathrm{p}=.021 ; \mathrm{b}=3.514)$, but expected life satisfaction in the future $(\mathrm{t}=.745 ; \mathrm{p}=.458)$ and age $(\mathrm{t}=-.153$; $\mathrm{p}=.879$ ) were not.

The older respondents (more than 20 years old; mean $=5.05$; $\mathrm{SD}=1.05$ ) and the younger respondents (up to 20 years old; mean $=4.98 ; \mathrm{SD}=1.38$ ) did not differ significantly in their life satisfaction now $(\mathrm{t}|103|=.223 ; \mathrm{p}=.824)$. The older respondents (more than 20 years old; mean $=5.9 ; \mathrm{SD}=1.41$ ) and the younger respondents (up to 20 years old; mean $=6.06$; $\mathrm{SD}=$ 1.084) did not differ significantly in their life satisfaction in the future $(\mathrm{t}|103|=.555 ; \mathrm{p}=.58)$.

The education influenced on the attitude towards $13-19$ year-old $(\mathrm{F}|4,109|=2.833 ; \mathrm{p}=.028)$ and on the attitude towards $20-25$ year-old $(\mathrm{F}|4,109|=3.701 ; \mathrm{p}=.007)$. The participants graduated from a lyceum had a more positive attitude towards $13-19$ year-old (Mean lyceum $=22.15 ;$ SD lyceum $=$ 28.2; Mean high school $=2$; $\mathrm{SD}$ high school $=21.2$; pLSD $=.002$ ) and a more positive attitude towards $20-25$ year-old $($ Mean lyceum $=42.38 ;$ SD lyceum $=22.1 ;$ Mean high school $=$ 24.29; SD high school $=21.1$; pLSD $=.004$ ) than the participants graduated from a high school did. The participants graduated from a lyceum had a more positive attitude towards $20-25$ year-old than the participants graduated from a university did (Mean university $=16.18$; SD university $=16.8$; $\mathrm{pLSD}=.003$ ). The respondents graduated from a technical school and these ones holding a $\mathrm{PhD}$ degree were too small in number.

There were not any significant differences between the studied students and workers in their attitude towards $13-19$ year-old $(\mathrm{F}|3,110|=1.677 ; \mathrm{p}=.176)$, in their attitude towards 20 - 25 year-old $(\mathrm{F}|3,110|=2.595 ; \mathrm{p}=.056)$. The studied pensioners and unemployed people were too small in number.

There were not any significant differences between the studied men and women in their attitude towards $13-19$ year-old $(\mathrm{F}|1,111|=2.348 ; \mathrm{p}=.128)$, in their attitude towards $20-25$ year-old $(\mathrm{F}|1,111|=.349 ; \mathrm{p}=.556)$.

There were not any significant differences between the married and single respondents in their attitude towards $13-19$ year-old $(\mathrm{F}|1,112|=1.511 ; \mathrm{p}=.222)$, in their attitude towards 20 - 25 year-old $(\mathrm{F}|1,112|=3.785 ; \mathrm{p}=.054)$.

There were not any significant differences between the re- 
spondents who did not have any children, the participants having 1 child, and the subjects with 2 children in their attitude towards $13-19$ year-old $(\mathrm{F}|2,111|=1.455 ; \mathrm{p}=.238)$, in their attitude towards $20-25$ year-old $(\mathrm{F}|2,111|=2.448 ; \mathrm{p}=.091)$.

Media content analysis revealed that the quoted sources and news items expressed mainly positive attitudes towards young people (only positive attitude in 44 news items $-27.7 \%$; more positive than negative attitude in 52 news items $-32.7 \%$ ) than negative attitudes (only negative attitudes in 12 news items $-7.6 \%$; more negative than positive attitude in 26 news items $-16.4 \%$ ) and neutral attitudes (in 25 news items -15.7\%). 72 news items $(45.3 \%)$ expressed adults' concern for young people.

The media described family issues in 46 news items in September 2010 . The media positive attitudes towards young people were related to family issues in 30 news items out of 46 $(65.2 \%)$

A young person's voice was quoted in 31 news items. In 16 news items out of them $(51.6 \%)$, a young person expressed positive attitudes towards young people. These positive attitudes towards young people were related to family issues, because a young person's voice was quoted in 15 news items dealing with family issues and in 11 news items out of them (73.3\%), a young person expressed his/her positive attitudes towards young people.

An example for a positive attitude towards young people related to family issues is: A businessman is plunged in loans in order to feed orphans (Telegraph, 15.09.2010).

Some examples for a negative attitude towards young people related to family issues are: a 21 year-old man from Yambol has transformed his flat into a home laboratory for production of meta-amphetamines (Telegraph, 17.09.2010). A grandmother and her grand-child cultivate cannabis (Telegraph, 25.09.2010).

\section{Discussion}

Regarding the first hypothesis, the increase of the age was related to a more positive attitude towards younger people from 13 to 19 . The older respondents (more than 20 years old) had a more positive attitude towards young people from 13 to 19 years old than the younger respondents (up to 20 years old) did. Bulgaria is moving towards individualism, but the collectivistic values are strengthened with the increase of age and the strongest individualism is in the age group of $15-18$ years old (Paspalanova, 1999: p. 138) where - the basic differentiation is not we-the others, but I versus the others (Hofstede, 2001; Hofstede, Pedersen, \& Hofstede, 2003: p. 110) and individualistic values of young people could explain this result (Hofstede, 2001; Hofstede, Pedersen, \& Hofstede, 2003: p. 110).

The older respondents (more than 20 years old) and the younger respondents (up to 20 years old) did not differ signifycantly in their attitudes towards young people from 20 to 25 . The elderly people's attitudes towards young people from 20 to 25 were not strongly positive. Young people in Bulgaria had positive attitudes towards young people, but not the most positive ones.

The image of young people reflected by the media was also predominantly a positive one.

Only educational groups in Bulgaria differed in their attitudes towards young people. The participants graduated from a lyceum had the most positive attitudes towards 13 - 19 year-old and towards $20-25$ year-old.
Regarding the hypothesis that people who feel satisfied are more likely to have positive attitude towards young people, it was proved that life satisfaction now and expected life satisfaction in the future were not related to a more positive attitude towards 13 - 19 year-old, but the increase of the participants' life satisfaction in the present time was related to a more positive attitude toward 20 - 25 year-old, and expected life satisfaction in the future was not. The participants in the study felt more community with $20-25$ year-old people that was pretty their own age group.

\section{References}

Adler, A. (1920). Practice and theory of individual psychology. Part 1. Sofia: Alegro.

Anderson, S., Bromley, C., \& Given, L. (2005). Public attitudes towards young people and youth crime in Scotland. Findings from the 2004 Scottish Social Attitudes Survey. Edinburgh: Scottish Centre for Social Research. URL (last checked in July 2010) www.scotland.gov.uk/socialresearch

Anglin, L., Johnson, S., Giesbrecht, N., \& Greenfield, T. (2000). Alcohol policy content analysis: A comparison of public health and alcohol industry trade newsletters. Drug and Alcohol Review, 19, 203-212. doi:10.1080/713659313

Bolzan, N. (2003). "Kids are like that!" Community attitudes to young people. National Youth Affairs Research Scheme. URL (last checked July 2010) www.deewr.gov.au/Youth/Programs/NYARS/Pages/03-05Publicatio ns.aspx

Fishbein, M. (1967). A behavior theory approach to the relations between beliefs about an object and the attitude toward the object. In M. Fishbein (Ed.), Readings in attitude theory and measurement (pp. 389-400). New York: John Wiley \& Sons.

Fishbein, M., \& Ajzen, I. (1975). Belief, attitude, intention, and behavior: An introduction to theory and research. Reading, MA: Addison-Wesley.

Hofstede, G. H. (2001). Cultures and organizations: Software of the mind. Sofia: Classic and Style LTD.

Hofstede, G. J., Pedersen, P. B., \& Hofstede, G. H. (2003). Exploring Culture: Exercises, stories, and synthetic cultures. Sofia: Classic and Style LTD.

Knibbe, R. A., Oostveen, T., \& Van De Goor, I. (1991). Young people's alcohol consumption in public drinking places: Reasoned behaviour or related to the Situation? British Journal of Addiction, 86, 1425-1433. URL (last checked July 2010)

www3.interscience.wiley.com/journal/119359982/abstract?CRETRY $=1 \&$ SRETRY $=0433$

Lampman, C., Rolfe-Maloney, B., David, E. J., Yan, M., McDermott, N., Winters, S., Davis, J., \& Lathrop, R. (2002). Messages about sex in the workplace: A content analysis of primetime television. Sexuality \& Culture, 6, 3-21. URL (last checked July 2010) www.springerlink.com/content/k6nqal etmyjje6xa/

McGuire, W. (1986). The vicissitudes of attitudes and similar representational constructs in twentieth century psychology. European Journal of Social Psychology, 16, 89-130.

doi:10.1002/ejsp.2420160202

Meshel, D. S., \& McGlynn, R.P. (2004). Intergenerational contacts, attitudes, and stereotypes of adolescents and older people. Educational Gerontology, 30, 457-459. URL (last checked July 2010) www.informaworld.com/smpp/content $\sim \mathrm{db}=\mathrm{all} \sim$ content $=\mathrm{a} 713770146$

Newspaper "Sega", all issues of September 2010.

Newspaper "Telegraph", all issues of September 2010.

Paspalanova, E. (1999). Psychological dimensions of individualism. Sofia: Academic Publishing House "Prof. Marin Drinov".

Prince, M., Stewart, R., Ford, T., \& Hotopf, M. (2003). Practical psychiatric epidemiology. Oxford: Oxford Medical Publications.

Romi, S. (1999). Normative youth's attitudes toward integrating detached youth within normative youth settings: Gender and field of studies differences. Child and Youth Care Forum, 28, 261-273. doi:10.1023/A:1021909409626 
Siperstein, G. N., Parker, R. C., Bardon, J. N., \& Widaman, K. F. (2007). A national study of youth attitudes toward the inclusion of students with intellectual disabilities. Exceptional Children, 73. URL (last checked July 2010)

www.accessmylibrary.com/article-1G1-165913485/national-study-y outh-attitudes.html

Stinnett, T. A., Cruce, M. K., \& Choate, K. T. (2004). Influences on teacher education student attitudes toward youth who are HIV+. Psychology in the Schools, 41. URL (last checked July 2010) www3.interscience.wiley.com/journal/106599095/abstract

Stoyanova, S., Eylem, O., Veskioja, B., McDermott, E., Bozhilov, D., Slavov, S., \& Voetmann, K. (2010). Attitudes towards and social represenations of young people. In: Slavchov, B., \& Lazarova, E. (Eds.), Social Cognition in Action (pp. 59-67). European Summer
School "Social Cognition", 17-24 July 2010, Blagoevgrad.

Turner, J. (1990). Social identification and formation of psychological groups. In: Todorova, E. (Ed.), Group and personality in social psychology: 14 West-European Scientists (pp. 65-87). Sofia: Science and Art.

Wagner, U., \& Zick, A. (1995). The relation of formal education to ethnic prejudice: Its reliability, validity and explanation. European Journal of Social Psychology, 25, 41-56.

doi:10.1002/ejsp.2420250105

Ward, J. (2005). An opportunity for engagement in cyberspace: Political youth web sites during the 2004 European Parliament Election Campaign. Information Polity, 10, 233-246, URL (last checked July 2010) www.portal.acm.org/citation.cfm?id=1412556 